\title{
Korelasi Indeks Prestasi Kumulatif Dengan NilaiUKMPPD CBT Periode November 2018 - Agustus 2019 Fakultas Kedokteran Universitas Riau
}

\author{
Rahmat Rezki ${ }^{1}$, Firdaus, ${ }^{2 *}$ Enikarmila Asni $^{3}$
}

\begin{abstract}
Academic achievement is an indication level of learning effort by someone. One of them is grade point average (GPA). Some researches showed correlation between GPA and medical competency test. This medical competency test consists of two parts: multiple choice question computer-based test (CBT) and an objective structured clinical examination (OSCE).. This cross sectional study aimed to determine the correlation of GPA with CBT scores for the period of November 2018 - August 2019 on students of Medical Faculty Riau University. The number of samples in this study were 149 students. GPA assessment were obtained from preclinical and clinical data of GPA. The majority GPA results are included in the value of 2.75-3.49 and have a percentage of 94\% (preclinical), 96\% (clinical) and 98.7\% (combined). CBT score $<66$ were obtained from $12.8 \%$ student while $87,2 \%$ students get score $\geq 66$. Spearman test showed significant correlation between GPA and CBT scores of students.
\end{abstract}

Keywords: Academic achievement, GPA, CBT

Uji kompetensi kedokteran adalah pengujian dan penilaian bersifat nasional bagi mahasiswa program profesi dokter, mencakup sikap, pengetahuan, dan keterampilan sebagai dasar untuk melakukan praktik kedokteran. ${ }^{1}$ Uji kompetensi untuk mendapatkan medical license telah dilakukan di berbagai negara dengan cara yang berbeda. Inggris menyelenggarakan PLAB (Professional and Linguistic Assessment Board); Kanada mengadakan MCCQE (Medical Council of Canada Qualifying Examination) yang memiliki dua tahap pengujian yaitu uji kognitif pada tahap pertama dan OSCE pada tahap kedua; Amerika dengan USMLE (United States Medical Licensing Examination) yang terbagi menjadi tiga tahap pengujian mencakup pengetahuan dasar,

\footnotetext{
* Correspondent author : Email: dr.firdaus@lecturer.unri.ac.id

1 Mahasiswa Fakultas Kedokteran Universitas Riau, Pekanbaru, Riau, Indonesia

2 KJFD Pendidikan Kedokteran, Fakultas Kedokteran Universitas Riau, Pekanbaru, Riau, Indonesia

3 KJFD Biokimia Fakultas Kedokteran Universitas Riau, Pekanbaru, Riau, Indonesia
}

kemampuan klinis (diagnosis maupun keterampilan) dan aplikasinya terhadap aktivitas kepaniteraan; negara Indonesia melaksanakan UKMPPD (Uji Kompetensi Mahasiswa Program Profesi Dokter) sebagai syarat registrasi untuk mengurus surat izin praktik dokter dalam rangka peningkatan standarisasi kualitas dokter. ${ }^{2}$

Implementasi UKMPPD sebagai exit exam sejak tahun $2014^{3}$ masih menyisakan permasalahan yaitu ketidaklulusan beberapa mahasiswa fakultas kedokteran yang mengikutinya sebagai first taker (UKMPPD peserta pertama). ${ }^{4}$ Exit exam atau ujian akhir adalah sebuah bentuk penilaian tertentu yang dilaksanakan pada institusi pendidikan dan perguruan tinggi yang bertujuan untuk menguji kemampuan dasar dari ilmu yang telah dipelajari oleh mahasiswa tersebut. Exit exam dapat membantu pihak universitas dalam menentukan keputusan dan kebijakan dalam rangka meningkatkan kualitas pendidikan di lingkungan mereka. Beberapa departemen atau institusi tertentu dapat membantu meningkatkan standar pendidikan di jurusan yang mereka jalankan. Mayoritas institusi perguruan tinggi 
mewajibkan mahasiswa untuk mengikuti dan lulus pada exit exam sebagai salah satu syarat kelulusan. ${ }^{5}$

Berdasarkan data dari Panitia Nasional UKMPPD sejak Agustus 2014 hingga Mei 2018 telah meluluskan sekitar 39.000 dokter dan menyisakan sekitar 2.494 ( $<8 \%$ dari total peserta yang telah mengikuti UKMPPD) yang belum lulus dan masih proses pembinaan. ${ }^{3}$ Berdasarkan data dari Koordinator Program Studi (KPS) Profesi Dokter Fakultas Kedokteran Universitas Riau tentang hasil kelulusan UKMPPD periode bulan November 2018 - Agustus 2019 terdapat total 149 mahasiswa yang mengikuti ujian dan persentase ratarata ketidaklulusan UKMPPD CBT sebesar 29,5\%.

Studi sebelumnya mengenai hubungan Indeks Prestasi Kumulatif (IPK) dengan uji standar kompetensi dokter pernah dilakukan di Amerika, penelitian ini menunjukkan bahwa terdapat hubungan antara IPK tahun ketiga dengan USMLE tahap 1. ${ }^{6}$ Studi di Kanada juga mendapatkan hasil yang serupa yaitu terdapat korelasi yang signifikan antara Licentiate of the Medical Council of Canada (LMCC) tahap 1 dengan IPK program sarjana kedokteran. Penelitian tersebut juga mengatakan bahwa IPK merupakan prediktor terbaik untuk menentukan hasil uji kognitif. ${ }^{7}$ Penelitian Pitra dan Akbar pada Fakultas Kedokteran Universitas Baiturrahmah didapatkan data bahwa terdapat korelasi negatif yang lemah antara IPK preklinik dengan pencapaian nilai UKMPPD CBT. ${ }^{8}$

Indeks prestasi kumulatif adalah cerminan hasil nilai capaian pembelajaran pada akhir program studi. ${ }^{9}$ Penelitian Pramana pada Universitas Diponegoro menyebutkan bahwa mahasiswa kedokteran yang telah dinyatakan lulus dapat dikatakan memiliki kompetensi sebagai seorang dokter dengan indikasi semakin tinggi IPK maka semakin tinggi pula kualitas individu sebagai seorang dokter. ${ }^{10}$
Berdasarkan uraian yang telah dikemukakan, peneliti tertarik untuk melaksanakan penelitian korelasi indeks prestasi kumulatif dengan nilai UKMPPD CBT periode November 2018 - Agustus 2019 Fakultas Kedokteran Universitas Riau.

\section{METODE}

Penelitian ini menggunakan rancangan analitik observasional dengan pendekatan cross sectional. Penelitian ini dilakukan di Fakultas Kedokteran Universitas Riau pada Desember 2019. Populasi penelitian ini adalah seluruh mahasiswa Fakultas Kedokteran Universitas Riau yang mengikuti UKMPPD periode November 2018 -Agustus 2019 sebanyak 149 orang. Penarikan sampel pada penelitian ini menggunakan metode sampel jenuh. Dimulai dengan mengambil data sekunder kepada pihak KPS Profesi Dokter Fakultas Kedokteran Universitas Riau untuk mendapatkan data hasil kelulusan UKMPPD CBT pada periode November 2018 - Agustus 2019 sebagai data pra riset dan mengambil nilai IPK klinik serta mengambil nilai IPK preklinik mahasiswa yang akan mengikuti UKMPPD pada periode November 2018 - Agustus 2019 dari Bagian Akademik Fakultas Kedokteran Universitas Riau. Pengolahan data sekunder dilakukan dengan aplikasi SPSS dan disajikan dalam bentuk tabel distribusi frekuensi dengan analisis univariat dan bivariat.

\section{HASIL}

Distribusi frekuensi IPK mahasiswa yang mengikuti UKMPPD periode November 2018 Agustus 2019 Fakultas Kedokteran Universitas Riau dapat dilihat pada tabel 1. Nilai IPK mahasiswa paling banyak berada dalam rentang nilai 2,75-3,49 secara berurutan sebesar 94\% (preklinik), 96\% (klinik) dan 98,7\% (gabungan). 
Tabel 1. Distribusi frekuensi indeks prestasi kumulatif mahasiswa yang mengikuti UKMPPD periode November 2018 - Agustus 2019 Fakultas Kedokteran Universitas Riau

\begin{tabular}{ccccccc}
\hline & \multicolumn{2}{c}{ IPK preklinik } & \multicolumn{2}{c}{ IPK klinik } & \multicolumn{2}{c}{ IPK gabungan } \\
\cline { 2 - 7 } Nilai IPK & $\mathrm{f}$ & $\%$ & $\mathrm{f}$ & $\%$ & $\mathrm{f}$ & $\%$ \\
\hline$<2,00$ & 0 & 0 & 0 & 0 & 0 & 0 \\
$2,00-2,74$ & 7 & 4,7 & 0 & 0 & 0 & 0 \\
$2,75-3,49$ & 140 & 94 & 143 & 96 & 147 & 98,7 \\
$3,50-3,99$ & 2 & 1,3 & 6 & 4 & 2 & 1,3 \\
4,00 & 0 & 0 & 0 & 0 & 0 & 0 \\
\hline Total & 149 & 100 & 149 & 100 & 149 & 100 \\
\hline
\end{tabular}

Tabel 2. Distribusi frekuensi nilai UKMPPD CBT mahasiswa yang mengikuti UKMPPD periode November 2018 - Agustus 2019 Fakultas Kedokteran Universitas Riau

\begin{tabular}{ccc}
\hline Nilai UKMPPD CBT & $\mathrm{f}$ & $\%$ \\
\hline$<66$ & 19 & 12,8 \\
$=66$ & 130 & 87,2 \\
\hline Total & 149 & 100 \\
\hline
\end{tabular}

Berdasarkan tabel 2 nilai UKMPPD CBT mahasiswa yang mengikuti UKMPPD periode November 2018 - Agustus 2019 Fakultas Kedokteran Universitas Riau termasuk ke dalam nilai $\geq 66$ sebanyak $87,2 \%$ dan nilai $<66$ sebanyak $12,8 \%$. Nilai minimum/maksimum UKMPPD CBT adalah 40 dan 90. Nilai rata-rata UKMPPD CBT adalah 74,5.

Tabel 3. Hasil uji statistik korelasi indeks prestasi kumulatif dengan nilai UKMPPD CBT mahasiswa yang mengikuti UKMPPD periode November 2018 - Agustus 2019 Fakultas Kedokteran Universitas Riau

\begin{tabular}{|c|c|c|c|c|c|c|c|c|c|c|c|c|c|}
\hline \multirow{3}{*}{ Nilai IPK } & \multirow{2}{*}{\multicolumn{2}{|c|}{$\begin{array}{c}\text { IPK } \\
\text { preklinik }\end{array}$}} & \multirow{2}{*}{\multicolumn{2}{|c|}{ IPK klinik }} & \multirow{2}{*}{\multicolumn{2}{|c|}{$\begin{array}{c}\text { IPK } \\
\text { gabungan }\end{array}$}} & \multicolumn{4}{|c|}{ Nilai UKMPPD CBT } & \multirow{2}{*}{\multicolumn{2}{|c|}{ Total }} & \multirow{3}{*}{$\begin{array}{c}p \\
\text { value }\end{array}$} \\
\hline & & & & & & & \multicolumn{2}{|c|}{$<666$} & \multicolumn{2}{|c|}{$=66$} & & & \\
\hline & f & $\%$ & f & $\%$ & f & $\%$ & f & $\%$ & f & $\%$ & f & $\%$ & \\
\hline$<2,00$ & 0 & 0 & 0 & 0 & 0 & 0 & 0 & 0 & 0 & 0 & 0 & 0 & \\
\hline $2,00-2,74$ & 7 & 4,7 & 0 & 0 & 0 & 0 & 6 & 85,7 & 1 & 14,3 & 7 & 4,7 & \\
\hline $2,75-3,49$ & 140 & 94 & 143 & 96 & 147 & 98,7 & 13 & 9,8 & 119 & 90,2 & 132 & 88,6 & 0,000 \\
\hline $3,50-3,99$ & 2 & 1,3 & 6 & 4 & 2 & 1,3 & 0 & 0 & 10 & 100 & 10 & 6,7 & \\
\hline 4,00 & 0 & 0 & 0 & 0 & 0 & 0 & 0 & 0 & 0 & 0 & 0 & 0 & \\
\hline \multicolumn{7}{|c|}{ Total } & 19 & & 130 & & 149 & 100 & \\
\hline
\end{tabular}

Berdasarkan tabel 3 diatas, dari $85,7 \%$ responden yang termasuk dalam nilai IPK 2,00-2,74 memiliki nilai UKMPPD CBT $<66$ dan $14,3 \%$ memiliki nilai UKMPPD CBT $\geq 66$. 90,2\% responden yang termasuk ke dalam nilai IPK 2,753,49 memiliki nilai UKMPPD CBT $\geq 66$ dan 9,8\% memiliki nilai UKMPPD CBT $<66.100 \%$ responden yang termasuk kedalam nilai IPK 3,50-3,99 memiliki nilai UKMPPD CBT $\geq 66$. Tidak ada responden yang memiliki nilai IPK $<2,00$ dan 4,00. Hasil Uji Spearman didapatkan $\mathrm{p}$ value $0,000(\mathrm{p}<0,05)$ yang berarti terdapat korelasi bermakna antara IPK dengan nilai CBT mahasiswa yang mengikuti UKMPPD periode November 2018 -Agustus 2019 Fakultas Kedokteran Universitas Riau. 


\section{PEMBAHASAN}

Penelitian ini menunjukkan bahwa sebagian besar responden $(88,6 \%)$ memiliki IPK dengan rentang 2,75-3,49, sisanya 4,7\% IPK 2,00-2,74 dan 6,7\% IPK 3,50-3,99. Hasil ini menunjukkan bahwa nilai IPK mahasiswa yang mengikuti UKMPPD periode November 2018 - Agustus 2019 Fakultas Kedokteran Universitas Riau mayoritas termasuk kedalam nilai baik karena IPK $\geq 2,00$ merupakan batas bawah kelulusan mahasiswa dengan predikat memuaskan. ${ }^{11}$ Hasil penelitian ini hampir sama dengan informasi penelitian Rakasiwi pada 75,2\% mahasiswa Fakultas Kedokteran Universitas Riau angkatan 2011 tahun ketiga yang memiliki rentang IPK 2,74 - 3,49. ${ }^{12}$

Nilai IPK dipengaruhi oleh berbagai faktor seperti faktor internal dan faktor eksternal. Faktor internal terdiri dari aspek jasmani (penglihatan, pendengaran dan struktur tubuh) dan aspek psikologi (intelektif, non-intelektif, kematangan fisik/psikis dan lingkungan spiritual/keamanan), sedangkan faktor eksternal terdiri dari aspek sosial (lingkungan tenaga kerja, lingkungan sekolah, lingkungan masyarakat dan lingkungan kelompok), aspek budaya (adat istiadat, ilmu pengetahuan, teknologi dan kesenian) dan aspek lingkungan fisik (fasilitas rumah, fasilitas belajar dan iklim). ${ }^{2}$

Hasil penelitian terhadap 149 orang mahasiswa yang mengikuti UKMPPD periode November 2018 - Agustus 2019 Fakultas Kedokteran Universitas Riau, didapatkan nilai UKMPPD CBT $\geq 66$ sebanyak 87,2\% dan nilai UKMPPD CBT <66 sebanyak $12,8 \%$. Penelitian ini menunjukkan bahwa nilai UKMPPD CBT mahasiswa yang mengikuti UKMPPD periode November 2018 - Agustus 2019 Fakultas Kedokteran Universitas Riau mayoritas termasuk nilai baik karena nilai <66 merupakan batas bawah kelulusan peserta UKMPPD CBT. ${ }^{1}$ Hasil penelitian ini hampir sama dengan yang dilakukan oleh Pratiwi pada mahasiswa Fakultas Kedokteran Universitas Padjadjaran yang mengikuti UKMPPD CBT periode Februari 2014 - Agustus 2016 sebanyak 524 mahasiswa dengan rerata skor UKMPPD CBT pada kesempatan pertama yaitu 77,65 (lulus). ${ }^{13}$

Uji kompetensi dipengaruhi oleh berbagai faktor seperti faktor internal dan faktor eksternal. Faktor internal terdiri dari aspek kemampuan akademik dan skills, kesehatan, kepercayaan diri mahasiswa, sedangkan faktor eksternal terdiri dari aspek kualitas pendidikan yang dilalui, pengalaman praktek, lingkungan sarana praktek yang mendukung dan proses bimbingan yang tepat. ${ }^{14}$ Uji kompetensi juga dipengaruhi oleh beberapa faktor seperti kemampuan akademik kognitif, kemampuan mahasiswa sebelum memasuki tahap perkuliahan, gaya belajar, pencapaian akademik di tahap sarjana dan pemahaman ilmu biomedik dasar. Penelitian lanjutan mengenai faktor lain yang dapat menjadi prediktor keberhasilan mahasiswa pada uji kompetensi nasional seperti proses pembelajaran di rotasi koas, hasil OSCE dan rubrik penilaian proses masih perlu dilakukan. Aspek demografi, jenis kelamin dan lain-lain juga bisa diteliti dengan lebih menyeluruh. ${ }^{13}$

Penelitian ini menunjukkan bahwa terdapat korelasi yang bermakna antara IPK dengan UKMPPD CBT, dimana p value dari uji spearman adalah 0,000 (nilai $\mathrm{p}<0,05$ ). Hasil penelitian ini sesuai dengan hipotesis penelitian. Kekuatan korelasi IPK dengan nilai UKMPPD CBT secara berurutan sebesar 0,732 (preklinik), 0,706 (klinik) dan 0,774 (gabungan). Korelasi IPK dengan UKMPPD CBT mahasiswa yang mengikuti UKMPPD Periode November 2018-Agustus 2019 Fakultas Kedokteran Universitas Riau memiliki interpretasi kuat dan arah yang postif. Semakin besar kedua nilai IPK preklinik maupun klinik maka semakin besar pula nilai UKMPPD CBT. Nilai IPK masih relevan dikatakan sebagai indikator learning outcome ataupun prediktor untuk menentukan hasil ujian kognitif. ${ }^{10,15}$ Hasil penelitian ini sesuai dengan penelitian Pratiwi, Pramana, Pusparini, Febrianti dan Mardi dimana didapatkan hasil korelasi yang bermakna antara IPK dengan nilai UKMPPD CBT. ${ }^{10,13,15-17}$

Korelasi antara IPK dengan nilai UKMPPD CBT (tabel 3) menunjukkan, mayoritas (85,7\%) mahasiswa dengan IPK preklinik $<2,75$ memiliki nilai UKMPPD CBT <66. Hal ini bisa menjadi peringatan kepada mahasiswa program pendidikan klinik yang memiliki IPK preklinik <2,75 supaya lebih meningkatkan usaha belajar dalam rangka memperbaiki ataupun mempersiapkan diri menghadapi UKMPPD CBT dengan lebih baik sehingga kemungkinan lulus akan lebih besar. 


\section{KESIMPULAN}

Sebagian besar IPK mahasiswa yang mengikuti UKMPPD periode November 2018 - Agustus 2019 Fakultas Kedokteran Universitas Riau mayoritas termasuk dalam nilai 2,75-3,49. Nilai CBT peserta yang mengikuti UKMPPD periode November 2018 - Agustus 2019 Fakultas Kedokteran Universitas Riau yang sebagian besar $(87,2 \%) \geq 66$. Terdapat korelasi positif yang kuat antara IPK dan nilai CBT pada peserta yang mengikuti UKMPPD periode November 2018-Agustus 2019 Fakultas Kedokteran Universitas Riau.

\section{DAFTAR PUSTAKA}

1. Panitia Nasional Uji Kompetensi Mahasiswa Program Profesi Dokter. Panduan Uji Kompetensi Mahasiswa Program Profesi Dokter [sambungan di Internet]. http:// aktivasi.pnukmppd.dikti.go.id/. Jakarta: Panitia Nasional Uji Kompetensi Mahasiswa Program Profesi Dokter; 2015 [dikutip 27 Agu 2019]. Diakses dari: http://aktivasi.pnukmppd.dikti.go.id/ berita/13-Panduan-Uji-Kompetensi-MahasiswaProgram-Profesi-Dokter.

2. Puspitasari AY. Korelasi indek prestasi kumulatif mahasiswa terhadap hasil kelulusan uji kompetensi mahasiswa program profesi dokter periode november 2014-mei 2015 Fakultas Kedokteran Universitas Lampung [skripsi]. Lampung: Universitas Lampung; 2015.

3. Kementerian Riset Teknologi dan Pendidikan Tinggi Republik Indonesia. Potret pendidikan kedokteran di Indonesia dalam menghadapi tantangan era revolusi industri 4.0 [sambungan di Internet]. https://ristekdikti.go.id/. 2018 [dikutip 29 Sep 2019]. Diakses dari: https:// ristekdikti.go.id/kabar/potret-pendidikankedokteran-di-indonesia-dalam-menghadapitantangan-era-revolusi-industri-4-0/.

4. Supriyati, Setiawati OR, Sandayanti V. Hubungan antara self efficacy (keyakinan kemampuan diri) dengan kelulusan retaker UKMPPD di Universitas Malahayati. Holistik J Kesehat. 2019;13(1):29-36.

5. What is exit exam [serial on the Internet]. www.tophat.com. [cited 2019 Aug 22]. Available from: https://tophat.com/glossary/e/exit-exam/.

6. Fields SA, Morris C, Toffler WL, Keenan EJ. Early identification of students at risk for poor academic performance in clinical clerkships. Acad Med. 2000;75(10):78-9.

7. Illing J, Campbell M, Kergon C, Thompson N, Burford B, Morrow G, et al. Selection methods for foundation programme/ : a literature review. 2009:43.

8. Pitra DA, Akbar RR. The correlation of preclinical GPA score in Faculty of Medicine of University of Baiturrahmah with national board examination result. Int J Med Sci Clin Invent. 2019;6(4):4403-6.

9. Rahmawati E. Hubungan gaya belajar terhadap indeks prestasi kumulatif (IPK) mahasiswa Fakultas Kedokteran Universitas Lampung [skripsi]. Jurnal Medula. Bandar Lampung: Universitas Lampung; 2016.

10. Pramana SW. Hubungan antara indeks prestasi kumulatif dengan nilai UKDI pada program pendidikan dokter/ : studi kasus FK UNDIP [skripsi]. Semarang: Universitas Diponegoro; 2011.

11. Peraturan Rektor Universitas Riau Nomor 3 Tahun 2015 tentang Peraturan Akademik Universitas Riau. Pekanbaru: 2015.

12. Rakasiwi PF. Hubungan harga diri dengan prestasi belajar mahasiswa tahun ketiga Fakultas Kedokteran Universitas Riau. J Online Mhs Fak Kedokt Univ Riau. 2014;1(2):4.

13.Pratiwi YS. Indeks Prestasi Kumulatif (IPK) CBT UKMPPD pada mahasiswa Fakultas Kedokteran Universitas Padjadjaran Periode 2015-2016. JK Unila. 2016;1(2):2-4.

14.Labatjo AI. Hubungan nilai ujian try out lokal dengan nilai computer based test uji kompetensi mahasiswa Program Profesi Dokter di Fakultas Kedokteran Universitas Sam Ratulangi Manado. J e-Biomedik. 2019;7(1):3.

15. Febrianti W. Hubungan IPK sarjana dan profesi dengan nilai CBT, OSCE, dan hasil UKMPPD di Fakultas Kedokteran Universitas Sam Ratulangi periode Mei dan Februari 2017. J eBiomedik. 2017;5(2). 
16. Mardi R. Hubungan indeks prestasi kumulatif dan lama studi dengan nilai uji kompetensi mahasiswa program profesi dokter peserta first taker Fakultas Kedokeran Universitas Andalas [skripsi]. Padang: Universitas Andalas; 2018.
17.Pusparini M. Hubungan antara IPK Program Sarjana Kedokteran dengan nilai UKMPPD mahasiswa FKUY. Juke Unila. 2016;1(2):23542. 